\title{
Cardiac Oxidative Stress and Inflammatory Cytokines Response after Myocardial Infarction
}

\author{
Margherita Neri ${ }^{1}$, Vittorio Fineschi ${ }^{1}$, Marco Di Paolo ${ }^{2}$, Cristoforo Pomara ${ }^{1}$, Irene Riezzo ${ }^{1}$, \\ Emanuela Turillazzi ${ }^{1}$ and Daniela Cerretani ${ }^{3}$
}

${ }^{I}$ Department of Forensic Pathology, University of Foggia, Ospedale Colonnello D'Avanzo, Viale degli Aviatori 1, 71100 Foggia, Italy; ${ }^{2}$ Department of Legal Medicine, University of Pisa; ${ }^{3}$ Department of Medical, Surgical Science and Neuroscience, University of Siena, Siena

\begin{abstract}
Oxidative stress in heart failure or during ischemia/reperfusion occurs as a result of the excessive generation or accumulation of free radicals or their oxidation products. Free radicals formed during oxidative stress can initiate lipid peroxidation, oxidize proteins to inactive states and cause DNA strand breaks. Oxidative stress is a condition in which oxidant metabolites exert toxic effects because of their increased production or an altered cellular mechanism of protection. In the early phase of acute heart ischemia cytokines have the feature to be functional pleiotropy and redundancy, moreover, several cytokines exert similar and overlapping actions on the same cell type and one cytokine shows a wide range of biological effects on various cell types. Activation of cytokine cascades in the infarcted myocardium was established in numerous studies. In experimental models of myocardial infarction, induction and release of the pro-inflammatory cytokines like TNF- $\alpha$ (Tumor Necrosis Factor $\alpha$ ), IL- $1 \beta$ (Interleukin-1 $\beta$ ) and IL-6 (Interleukin-6) and chemokines are steadily described. The current review examines the role of oxidative stress and pro-inflammatory cytokines response following acute myocardial infarction and explores the inflammatory mechanisms of cardiac injury.
\end{abstract}

Keywords: Cardiac oxidative stress, Chemokine, IL-1 $\beta$, IL-6, MCP-1, Myocardial infarction, TNF- $\alpha$.

\section{INTRODUCTION}

Myocardial infarction remains the greatest killer in the Western world, and is the leading cause of chronic heart failure [1]. Although early reperfusion is the only way to salvage an ischemic organ, during the crucial early moments of reperfusion, significant reversible and irreversible organ damage is initiated, and is referred to as reperfusion injury. Reperfusion injury includes arrhythmias, transient mechanical dysfunction of the heart or "myocardial stunning", microvascular injury and "no-reflow", as well as inflammatory responses. In reperfusion, cell death can occur due to apoptosis, necrosis, and autophagy [2-8]. Reperfusion therapy must be performed as soon as possible after myocardial infarction in order to attenuate the ischemic injury. However, reperfusion is responsible for additional myocardial damage. One hypothesis is that antioxidants are extensively consumed during infarction and $\mathrm{O}_{2}$ abruptly increases metabolism after reperfusion in the absence of normal defenses [9]. This hypothesis has led to the proposal of myocardial anti-oxidative conditioning. However, although several studies have reported on the beneficial effect of certain antioxidants, this has been refuted by others [10-14], but supported by studies involving cardiac surgery $[12,15]$. Furthermore, several researches demonstrated that inflammatory processes are

*Address correspondence to this author at the Department of Forensic Pathology, University of Foggia, Ospedale Colonnello D'Avanzo, Viale degli Aviatori 1, 71100 Foggia, Italy; Tel: 0039881736901; Fax: 0039881736901; E-mail: marghertaneri@hotmail.com involved in cardiovascular injury resulting from ischemia and/or reperfusion, thrombosis, and infection $[16,17]$. For example, myocardial inflammation has been implicated as a secondary injury mechanism after ischemia and reperfusion [18].

Activation of cytokine cascades in the infarcted myocardium was established in numerous studies [19-21]. In experimental models of myocardial infarction, induction and release of the pro-inflammatory cytokines like TNF- $\alpha$ (Tumor Necrosis Factor $\alpha$ ), IL-1 $\beta$ (Interleukin-1 $\beta$ ) and IL-6 (Interleukin-6) are steadily described [21-23]. The inflammatory response is a multifaceted system made by many components and their interactions, the inflammatory molecules and pathways are closely related and change cellular physiology, leading to various pathologies in the cardiovascular system $[16,17]$. Inflammation is also a major component of the damage caused by infectious diseases such as myocarditis and rheumatic heart disease and is also a fundamental contributor to atherosclerosis, ischemic heart disease, and heart failure, as well as transplant vasculopathy and stroke [16].

Cytokines have the feature to be functional pleiotropy and redundancy, moreover, several cytokines exert similar and overlapping actions on the same cell type and one cytokine shows a wide range of biological effects on various cell types [24]. The multifunctional, overlapping and often contradictory effects of the cytokines have hindered understanding of their functional role in cardiac injury and repair. In the infracted area is present a marked cytokine upregulation due to various mechanisms like Reactive Oxygen Species (ROS) 
generation, complement activation, and NF- $\kappa \mathrm{B}$ (nuclear factor kappa-light-chain-enhancer of activated B cells) activation potently stimulate cytokine mRNA (Messenger Ribonucleic acid) synthesis in both resident and blood-derived cells [25].

The current review examines the role of oxidative stress and pro-inflammatory cytokines response following acute myocardial infarction and explores the inflammatory mechanisms of cardiac injury.

\section{OXIDATIVE STRESS}

\subsection{Free Radicals and Oxidative Stress}

Oxidative stress in heart failure or during ische$\mathrm{mia} /$ reperfusion occurs as a result of the excessive generation or accumulation of free radicals or their oxidation products. Free radicals formed during oxidative stress can initiate lipid peroxidation, oxidize proteins to inactive states and cause DNA (Deoxyribonucleic acid) strand breaks [26]. Free radicals are molecules and atoms with unpaired electrons in their outer shell. They are highly reactive and are formed in processes that involve oxygen. Free radicals that originate from oxygen are called Reactive Oxygen Species (ROS), whereas free radicals that originate from the reaction of oxygen with nitrogen are considered a subclass of free radicals and are called reactive nitrogen species (RNS).

In the case of oxygen, its univalent reduction leads to the formation of superoxide $\left(\mathrm{O}_{2}^{-}\right)$anion, which serves a key role in the generation of other more reactive species such as hydroxyl $(\mathrm{OH})$ radical. The $\mathrm{OH}$ radical can be formed by two pathways: 1) the hydrogen peroxide $\left(\mathrm{H}_{2} \mathrm{O}_{2}\right)$ spontaneously combined to form molecular oxygen, $\mathrm{OH}^{-}$and $\mathrm{OH}$ radicals; 2) the Fenton reaction where $\mathrm{H}_{2} \mathrm{O}_{2}$ accepts an electron from a reduced metal ion such as $\mathrm{Fe}^{2+}$. Superoxide serves a critical role here as well since it is the primary reducing agents to replenish the reduced metal ion. The high reactivity of the $\mathrm{OH}$ radical causes it to react at diffusion-limited rates, and it reacts with the first molecule it comes into contact such as unsaturated fatty acid side chains resulting in lipid peroxidation and disruption of cell membranes [27, 28]. Singlet oxygen $\left({ }^{1} \mathrm{O}_{2}\right)$, the electronically excited state of molecular oxygen is one of its more reactive and toxic forms. The activation of molecular oxygen to that energetic state with antiparallel spin (singlet state) requires overcoming of spin restriction. Singlet oxygen has a non-radical and electrophilic character. Thus, ${ }^{1} \mathrm{O}_{2}$ can induce oxidative reactions with organic compounds in its electron-rich moieties without the participation of free radicals. The high reactivity of ${ }^{1} \mathrm{O}_{2}$ with biological macromolecules makes it a potential aggressor when produced within the cell. This has been observed specially by its ability to damage guanine components and nucleic acids, with toxic and mutagenic effects [29]. Mechanisms for the enzymatic formation of ${ }^{1} \mathrm{O}_{2}$ have been proposed to occur in several cases, including as part of the host immune defenses in inflammatory processes. It is believed that different cellular types, such as eosinophils, macrophages and neutrophils can generate this oxidant in response to inflammation $[30,31]$. RNS are another group of free radicals generated during ischemia-reperfusion from an ironindependent reaction involving the interaction of $\mathrm{O}_{2}{ }^{-}$and the nitric oxide (NO). RNS include nitric oxide (NO), nitrogen dioxide $\left(\mathrm{NO}_{2}\right)$ and peroxynitrite $\left(\mathrm{ONOO}^{-}\right)$, the latter being originated by a reaction of $\mathrm{O}_{2}-$ with NO [32]. Such RNS may have biologic activities distinct from those of the parent molecules [33-41]. In particular, in a biological system where $\mathrm{O}_{2}$ or superoxide are present, $\mathrm{NO}$ may be considered a reactive radical, when involved in the so-called "indirect effects" while NO "direct effects" are defined as those reactions occurring between NO and specific biological molecules [40]. During reperfusion a large burst of NO is produced primarily from nitric oxide synthase (NOS). In the same time frame large amounts of $\mathrm{O}_{2}-$ are also generated. The overwhelming affinity of $\mathrm{NO}$ and $\mathrm{O}_{2}-$ ensures their rapid reactivity during the initial moment of reperfusion to form ONOO- [42]. One of proposed mechanisms of cardiac dysfunction in heart failure is the excessive production of NO in the heart, especially in myocytes [43]. Circulatory proinflammatory cytokines found in high concentrations in plasma of patients with heart failure [44] stimulate the expression of inducible NOS, with consequent over-production of NO. NO has negative inotropic effects and induces apoptosis at high concentrations in vitro [45].

Hydrogen peroxide $\left(\mathrm{H}_{2} \mathrm{O}_{2}\right)$, which is not a free radical, is considered with ROS because it is very reactive. It can be formed from superoxide anion and can generate hydroxyl radicals. In fact, strong oxidants are produced through Fenton-type reactions of $\mathrm{H}_{2} \mathrm{O}_{2}$ with transition metal complexes [2, 33-41].

Oxidative stress occur when there is "an increased generation of superoxide anion and hydrogen peroxide which overwhelms the normal cellular defence mechanisms" [46] and this results in oxidative damage. By their nature ROS can attack all cellular targets nonspecifically causing alteration of membrane integrity and permeability. ROS also denature proteins determining a loss in enzyme activity. As well as this they interfere with the sarcoplasmic reticulum calcium transport and potentiate inflammatory responses by acting as chemotactic agents. Unbalanced cellular redox status can impair signal transduction protein synthesis, enzyme activation and even regulation of the cell cycle $[28,47$, 48]. Alteration in membrane proteins by free radicals is among the important factors in the evolution of myocardial ischemia/reperfusion damage; oxygen free radicals can attack subcellular structures resulting in metabolic and structural changes leading ultimately to apoptosis and necrosis [26].

\subsection{Sources of Free Radicals, Myocardial Oxidative Damage, and Antioxidant Defence Systems}

Oxidative stress is a condition in which oxidant metabolites exert toxic effects because of their increased production or an altered cellular mechanism of protection. The heart needs oxygen but it is also susceptible to oxidative stress, which occurs during post-ischaemic reperfusion, for example. Ischaemia causes alterations in the defence mechanisms against oxygen free radicals; at the same time, production of oxygen free radicals increases. Several possible sources of free radicals in the myocardium are described [3] and the mitochondria, myocardial cell membranes and endothelial cells are all potential sites of free radical production $[42,49$, 50]. These sources included: the enzymes xanthine oxi- 
doreductase, the major source of superoxide in postischemic tissue [11]; NADPH oxidase (multisubunit membrane complexes), NO synthases and mitochondrial cytochromes [33$41,51,52]$. The mitochondria are considered the main source of ROS in myocardium [3] and they can produce ROS from respiratory complex, Monoamine oxidase and p66Shc [52]. Their role during ischemia/reperfusion is particularly critical because of the conditions that promote both apoptosis by the mitochondrial pathway and necrosis by irreversible damage to mitochondria in association with mitochondrial permeability transition (MPT). MPT is caused by the opening of permeability transition pores in the inner mitochondrial membrane, leading to matrix swelling, outer membrane rupture, release of apoptotic signaling molecules such as cytochrome c from the intermembrane space, and irreversible injury to the mitochondria. During ischemia, factors such as intracellular $\mathrm{Ca}^{2+}$ accumulation, long-chain fatty acid accumulation, and ROS progressively increase mitochondrial susceptibility to MPT, increasing the likelihood that MPT will occur on reperfusion [53]. Other potential source of oxygen radicals include superoxide anion production from autoxidation of catecholamines via adrenochrome formation and from activated neutrophils. ROS, which are known to generate oxidative stress and produce cardiotoxic effects, including arrhythmias, are formed during the oxidation of catecholamines; the levels of catecholamines which are abundantly released from the ischemic myocardium are increased in plasma during ischemia and subsequently their autoxidation could provide ROS trough the formation of adrenochromes and potentially induces myocardial damage [54-58]. The oxidation products of catecholamines have been demonstrated to produce subcellular alterations, intracellular $\mathrm{Ca}^{2+}$-overload, coronary spasm, myocardial cell damage, depletion of high energy stores, and ventricular arrhythmiasm [59]. Because intracellular $\mathrm{Ca}^{2+}$ overload is known to activate different proteases and phospholipases, it is likely that the cardiotoxic effects of high concentrations of catecholamines may be occurring upon the disruption of some proteins, which control subcellular functions, and/or accumulation of some phospholipids intermediates, which affect cardiac rhythms adversely $[60,61]$.

The superoxide anion can also be produced from the cyclooxygenase pathway of arachidonic acid metabolism during ischemia $[49,50,54,62]$. In fact, calcium activation of phospholipases degrades cell membrane phospholipids that releases arachidonic acid. This is metabolized via cyclooxygenase and lipooxygenase to prostaglandins and leukutrienes. These metabolic patways involve electron transfer that can initiate the formation of free radicals [28, 49, 50, 63, 64]. Activated neutrophils during reperfusion represent a potential source of ROS. The inflammatory response to ischemiareperfusion cause the release of substances with chemotactic activity that induces neutrophils infiltration and activation. They then adhere to injured endothelium where they initiate the production of ROS via NADPH oxidase on their cell membrane, which reduces molecular oxygen to superoxide anion and oxidize NADPH to NADP+ [28, 62, 65]. ROS generated during the early stages of post ischemic reperfusion can induce lipid peroxidation and oxidative injury that result in alteration of membrane permeability and membrane lipid bilayer disruption. ROS also denature proteins causing a loss of normal enzyme activity $[28,47,48,66]$. In addition, alterations in myocyte function due to oxidative stress are associated with the effects of free radicals on subcellular organelles. ROS have been involved in contractile dysfunction and hypercontracture. They have been shown to disrupt sarcolemma and ATPase $\mathrm{Ca}^{2+}$ transport activity and subsequently to induce $\mathrm{Ca}^{2+}$ overload and impair sarcoplasmic reticulum function $[63,67]$. The critical role of intracellular $\mathrm{Ca}^{2+}$ overload in the genesis of myocyte dysfunction has been well established [68]. In general, $\mathrm{Ca}^{2+}$-overload can be induced by direct effect of ROS on $\mathrm{Ca}^{2+}$-handling proteins or indirectly, by inducing membrane lipid peroxidation. In addition, other mechanisms involving an increase in the concentration of $\mathrm{Na}+$ and accumulation of long chain fatty acids in cardiac membranes should be considered. Deficiency in ATP in the ischemic heart may also impair $\mathrm{Ca}^{2+}$-handling mechanisms in the sarcolemmal and sarcoplasmic reticular membranes and thus induce $\mathrm{Ca}^{2+}$-overload. Reperfusion of the ischemic heart may also increase the uptake of extracellular $\mathrm{Ca}^{2+}$ into the myocardium and thus be another factor for $\mathrm{Ca}^{2+}$ overload. Intracellular $\mathrm{Ca}^{2+}$-overload seems to be a common denominator for vasoconstriction for the development of hypertension, myocardial cell damage observed in ischemiareperfusion, and cardiac hypertrophy in heart failure [69].

Exposure to free radicals from a variety of sources has led organisms to develop a series of defence mechanisms. Defence mechanisms against free radical-induced oxidative stress in the heart involve enzymatic and non-enzymatic antioxidant defences. Enzymatic antioxidant defences include superoxide dismutase (SOD), glutathione peroxidase (GPx), catalase (CAT). Non-enzymatic antioxidants are represented by ascorbic acid (Vitamin C), $\alpha$-tocopherol (Vitamin E), glutathione (GSH), carotenoids, coenzyme Q, thioredoxins. Under normal conditions, there is a balance between both the activities and the intracellular levels of these antioxidants. The major thiol antioxidant and redox buffer of the cell is the tripeptide, GSH [70]. The oxidised form of glutathione is GSSG, glutathione disulphide. Oxidised glutathione is accumulated inside the cells and the ratio of GSH/GSSG is a good measure of oxidative stress of an organism. Too high a concentration of GSSG may damage many enzymes oxidatively. The main protective roles of glutathione against oxidative stress are [70] to take part as a cofactor of several detoxifying enzymes against oxidative stress; to scavenge hydroxyl radical and singlet oxygen directly, detoxifying hydrogen peroxide and lipid peroxides by the catalytic action of glutathione peroxidase; to regenerate the most important antioxidants, Vitamins $\mathrm{C}$ and $\mathrm{E}$, back to their active forms. The capacity of glutathione to regenerate the most important antioxidants is linked with the redox state of the glutathione disulphide-glutathione couple (GSSG/2GSH) [71]. The most important antioxidative enzymes of the heart are SOD, CAT and GPx. SOD catalyzes the dismuation of $\mathrm{O}_{2}-$ to hydrogen peroxide $\left(\mathrm{H}_{2} \mathrm{O}_{2}\right)$. Catalase and peroxidase remove $\mathrm{H}_{2} \mathrm{O}_{2}$ and, moreover, GPx can reduce lipid peroxides. Under normal conditions an equilibrium exists between the formation and removal ROS. If ROS are formed in excess or the defensive antioxidative mechanism are inefficient, oxidative stress develops [3, 69]. Free radical-scavenging enzymes such as SOD and CAT are the first line of cellular defense against oxidative injury, decomposing $\mathrm{O}_{2} \cdot-$ and $\mathrm{H}_{2} \mathrm{O}_{2}$ before interact- 


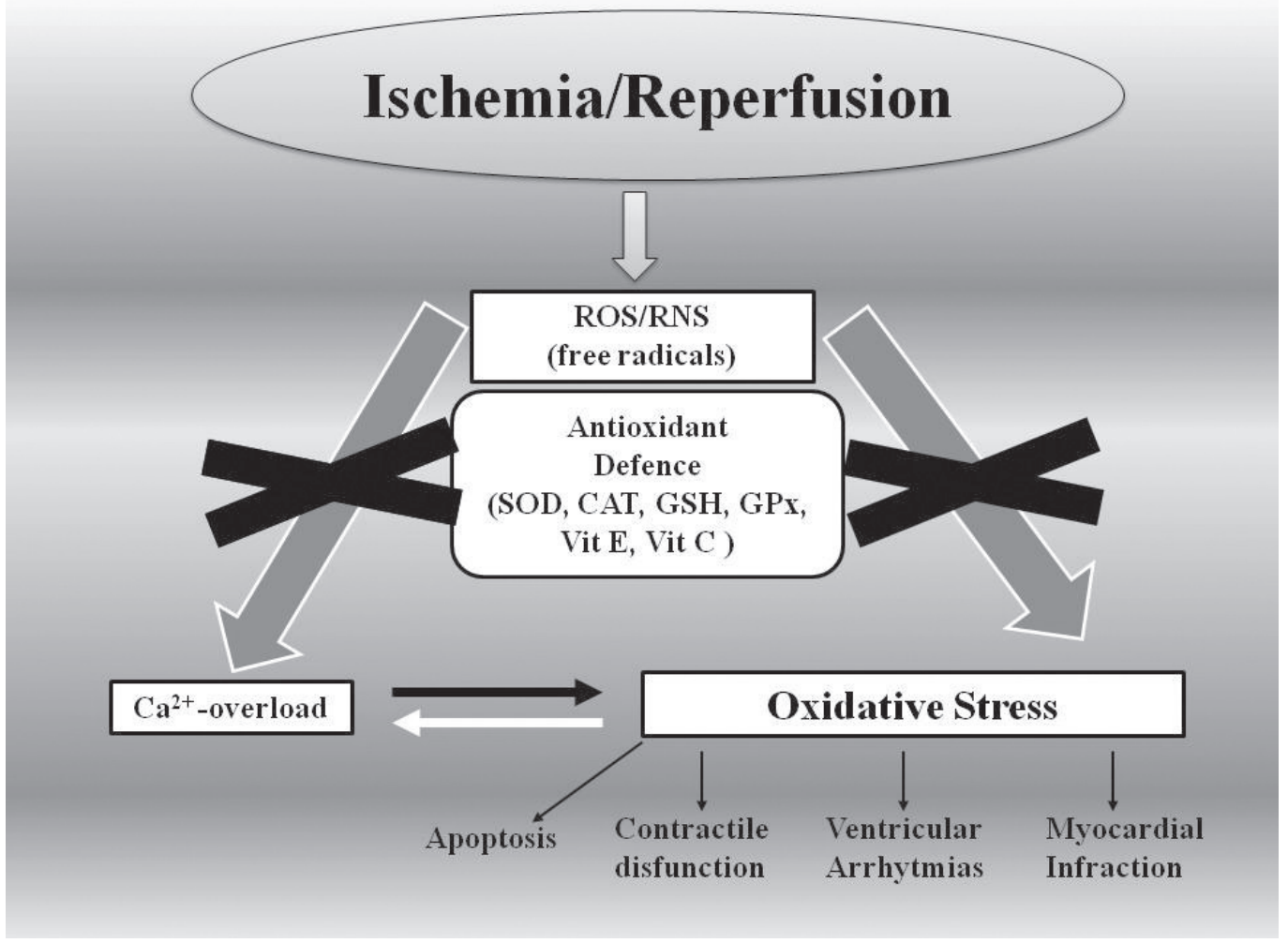

Fig. (1). Role of oxidative stress and antioxidant defense in the heart following ischemia/reperfusion.

ing to form the more reactive hydroxyl radical $(\mathrm{OH})[11,72]$ showed that CAT activity significantly increased after reperfusion, suggesting that the antioxidant defense system protects the cell against reactive species. High levels of SOD and CAT were found in patients with coronary heart disease by Weinbrenner et al. [73] and Kesavulu et al. [74], respectively. Bagatini et al. [75], also observed an increase in SOD and CAT activities in whole blood of myocardial infarction patients. A possible explanation for this is that the rise in SOD and CAT activity could be a compensatory mechanism to prevent tissue damage caused by oxidative stress [74]. Conversely, Senthil et al. [76] and Pandey et al. [77] observed decreasing SOD and CAT activities in erythrocytes of cardiogenic shock patients and in human blood platelets in myocardial infarction. These findings may be explained by a decrease in antioxidant enzymes followed by an increase in their activity levels after ROS generation, such as in myocardial injury followed by reperfusion [78]. Another point to be discussed here is that SOD and CAT are intracellular enzymes that can also increase due to tissue damage in myocardial infarction. In the same line of thought, NikolicHeitzler et al. [79], studying oxidative stress in myocardial infarction patients treated by percutaneous coronary intervention, found an increase in antioxidant capacity, and this rise was assigned to the release of intracellular antioxidants caused by tissue damage in myocardial infarction (Fig. 1).

\section{PRO-INFLAMMATORY CYTOKINES AFTER MYOCARDIAL INFARCTION}

\subsection{TNF- $\alpha$}

TNF- $\alpha$ belongs to a superfamily of ligand/receptor proteins called the tumor necrosis factor/tumor necrosis factor receptor superfamily proteins (TNF/TNFR SFP). TNF- $\alpha$ possess a trimeric symmetry with a structural motif called the TNF homology domain (THD), which is shared with all other members of the TNF proteins. This THD binds to the cysteine-rich domains (CRDs) of the TNF receptors (TNFRs), and variations of these CRDs lead to heterogeneity of the TNFRs [80]. TNFRs are either constitutively expressed (TNFR1, p55-R) or inducible (TNFR2, p75-R) [81].

TNF- $\alpha$ is able of exerting diverse effects on all cell types implicated in cardiac injury and repair. TNF- $\alpha$ improves cardiomyocyte apoptosis [82]. Suppresses cardiac contractility $[83,84]$ and stimulates expression of chemokines, proinflammatory cytokines and adhesion molecules by endothelial cells and leukocytes, in addition regulates extracellular matrix metabolism, in cardiac fibroblasts, by enhancing Matrix metalloproteinases activity and by decreasing collagen synthesis [85].

Various studies tried to explain the diverse effects of TNF- $\alpha$ in the infarcted myocardium. Sun et al. demonstrated that elevated local TNF- $\alpha$ in the infarcted myocardium contributes to acute myocardial rupture and chronic left ventricle dysfunction by inducing exuberant local inflammatory response, matrix and collagen degradation, increased matrix metalloproteinase activity, and apoptosis [86].

Several other studies have demonstrated an essential role for TNF- $\alpha$ in mediating inflammatory injury following infarction $[23,87]$.

Contradictory findings regarding the effects of TNF- $\alpha$ neutralization on the infarcted heart were found in inhibition studies. Several studies demonstrated injurious effects of TNF- $\alpha$ signaling in mediating infarct expansion and cardiac 
dysfunction. In particular Berthonneche et al. demonstrated that TNF- $\alpha$ plays a major role in cardiac alterations 7 days after myocardial infarction in rats and contributes to hemodynamic derangement, but not to cardiac remodeling, in subsequent Cardiac Heart Failure [88] and Sugano et al. proved that the suppression of TNF-alpha bioactivity from the early stage of infarction with the Soluble TNF-alpha receptor 1 plasmid improved cardiac function and reduced infarct size [89].

While other authors indicated protective effects of TNF- $\alpha$ signaling in the infarcted myocardium. Moden et al. demonstrated that the TNF- $\alpha$ inhibition using gene therapy with soluble TNF alpha receptor had deleterious effects in a mouse infarction model promoting cardiac rupture and enhancing adverse remodeling [90].

In addition, Kurrelmeyer et al. in an animal experimental study showed that the peak frequency and extent of apoptosis were accelerated in the TNFR1/TNFR2-deficient mice when compared with the wild-type mice. The increase in apoptosis in the TNFR1/TNFR2-deficient mice did not appear to be secondary to a selective up-regulation of the Fas ligand/ receptor system in these mice. These data suggest that TNF signaling gives rise to one or more cytoprotective signals that prevent and/or delay the development of cardiac myocyte apoptosis after acute ischemic injury [91].

The results of these studies showed that TNF- $\alpha$ may induce cytoprotective signals able of preventing or delaying the development of myocyte apoptosis after myocardial infarction. TNF- $\alpha$ may exercise distinct biological effects through the TNFR1 and TNFR2 receptor. Monden et al. suggest that effects mediated through TNFR1 are harmful, inducing cardiac dysfunction, whereas TNFR2-mediated actions may be protective by attenuating adverse remodeling [92].

In a recent study, Yu et al. investigated direct effects of hypoxia on TNF- $\alpha$ expression of cardiomyocytes, the role of hypoxia inducible factor- $1 \alpha(\mathrm{HIF}-1 \alpha)$ in $\mathrm{TNF}-\alpha$ regulation and potential secretory pathway of TNF- $\alpha$. Elevated TNF- $\alpha$ expression and HIF-1 $\alpha$ activation in primary cultured cardiomyocytes under hypoxia were detected by real-time PCR, Western blotting and immunofluorescence. Results of this study indicate that under hypoxia, HIF- $1 \alpha$ initiates expression of TNF- $\alpha$, mediated by exosomes in cardiomyocytes [93].

The contradictory findings of the various studies about the role of TNF- $\alpha$ in myocardial infarction highlight the complex and pleiotropic actions of the cytokines in biological processes and may explain the unpredictable effects of cytokine-targeted therapeutic strategies in clinical trials for example the clinical significance of early TNF- $\alpha$ elevation in patients ST-segment elevation myocardial infarction (STEMI) and successful primary percutaneous coronary intervention (PCI) [94].

\subsection{IL-1 Family}

The Interleukin-1 (IL-1) gene family consists of three members: IL-1 $\alpha$, IL-1 $\beta$ and IL-1 receptor antagonist (IL1ra). IL- $1 \alpha$ and IL-1 $\beta$ play an agonist role, while IL-1ra is a specific receptor antagonist [95].
IL- $1 \alpha$ and IL-1 $\beta$ are able to induce the release and function of chemokines, growth factors, other cytokines, and adhesion molecules. In several experimental models of myocardial infarction has been demostreted an upregulation of IL- $1 \alpha$ and IL- $1 \beta[19,96]$.

In patients affected by acute myocardial infarction has been recorded, a significant increase of IL-1 $\beta$ plasma levels [97]. Suzuki et al. demonstrated that IL-1ra introduced by gene transfection protected myocardium from ischemiareperfusion injury by attenuating the inflammatory response, which was associated with decreased apoptosis. This suggests a potentially important role of IL-1/IL-1 ra in myocardial ischemia-reperfusion injury and the value of IL-1ra-gene therapy for myocardial preservation; so, this study advances an injurious role for IL-1 in the ischemic myocardium [98].

In opposition of the study of Suzuki et al. another investigation performed by Hwang et al. suggested a protective role of IL-1 in myocardial infarction demonstrating that IL$1 \beta$ neutralization in the acute phase of myocardial infarction caused an increase of cardiac rupture and enhanced adverse remodeling [99].

The proinflammatory cytokine interleukin IL-1 signals exclusively through the type I IL-1 receptor (IL-1RI). IL-1 expression is markedly induced in the infarcted heart; however, its role in cardiac injury and repair remains controversial [100]. Following reperfused infarction IL-1RI null mice exhibited decreased infiltration of the infarcted myocardium with neutrophils and macrophages and reduced chemokine and cytokine expression. IL-1 signaling is essential for activation of inflammatory and fibrogenic pathways in the healing infarct, playing an important role in the pathogenesis of remodeling after infarction. Thus, interventional therapeutics targeting the IL-1 system may have great benefits in myocardial infarction $[100,101]$.

Different studies have identified a role of IL-1 in the development of adverse cardiac remodeling. However, in animal models of Acute myocardial infarction IL-1 has been shown to be cardioprotective in preconditioning, raising the question of clinical safety of therapeutic IL-1 blockade for autoinflammatory diseases or for the prevention or the treatment of Acute myocardial infarction. Toldo et al. proposed to evaluate the effects of pretreatment with recombinant human interleukin-1 receptor antagonist (rhIL-1Ra) on ischemia reperfusion $(\mathrm{I} / \mathrm{R})$ injury to the heart and showed that IL1 blockade therapies using rhIL-1Ra prior the onset of Acute myocardial infarction protects the myocardium and preserves cardiac function in an animal model [102].

\subsection{The IL-6 Family of Cytokines}

The family of IL (interleukin)-6-type cytokines comprises IL-6, IL-11, LIF (leukaemia inhibitory factor), OSM (oncostatin M), CNTF (ciliary neurotrophic factor), CT-1 (cardiotrophin-1) and CLC (cardiotrophin-like cytokine) and neurotrophin-1/B-cell stimulating factor-3 (NNT-1/BSF-3). They activate target genes involved in differentiation, survival, apoptosis and proliferation. The members of this cytokine family have pro- as well as antiinflammatory properties and are major players in haematopoiesis, as well as in acutephase and immune responses of the organism. All IL-6- 
related cytokines signal through multisubunit receptors that share the transmembrane glycoprotein (gp)130. Many experimental studies demonstrated induction of members of the IL-6 family in healing infarcts [103].

In the ischemic myocardium, the IL-6 synthesis is quickly induced in mononuclear cells and cardiomyocytes $[23,104,105]$.

In fibroblasts and surviving cardiomyocytes the Cardiotrophin-1 is upregulated and manifests a delayed period of expression [103, 106], while LIF [22] and oncostatin-M [107] are induced during the inflammatory phase of healing.

Despite the numerous studies performed the functional role of IL-6 in infarct healing remains unknown. Members of the IL-6 family have intense effects on cardiac myocytes both in the protection from apoptosis and promotion of cardiac hypertrophy [108].

CT-1 can protect adult cardiac cells both in vitro and in vivo when added both prior to or after the hypoxic/ischemic stimulus. CT-1 administration resulted in decreased infarct size and reduced cardiomyocyte apoptosis in a rat model of myocardial ischemia and reperfusion [109]. In a mouse model of reperfused infarction, CT-1 absence did not modified infarct size, so the study suggest that endogenous CT-1 does not play an essential role in acute ischemic cardiac injury [110]. While a prolonged CT-1 upregulation in the infracted myocardium may modulate the fibrotic response through effects on fibroblast proliferation [111].

The role of endogenous LIF expression in the infarct remains is not well known, LIF enhances survival of cardiomyocytes and induces regeneration of myocardium after myocardial infarction and induced angiogenesis, improving recruitment of bone marrow-derived cells into the heart [112].

IL-6 is able of modulating the phenotypic characteristics and gene expression of many cell types involved in infarct healing [113]. However, Fuchs et al. [114] found that the absence of IL-6 did not affect infarct size, left ventricular function and post-infarction remodeling in non-reperfused infarcts.

\subsection{The Chemokine Family in Myocardial Infarction}

Chemokines are a family of small cytokines, or proteins (8-14 kDa) secreted by cells with a strikingly similar tertiary structure. Their name is derived from their ability to induce directed chemotaxis in nearby responsive cells; they are chemotactic cytokines. Proteins are classified as chemokines according to shared structural characteristics such as small size, and the presence of four cysteine residues in conserved locations that are key to forming their 3-dimensional shape [115]. Chemokines are divided into subfamilies on the basis of the number and sequential relationship of their conserved cysteine residues (CXC, CC, XCand CX3C subfamilies). The principal targets of Chemokines are bone marrowderived cells they have a fundamental role in basal and inflammatory leukocyte locomotion and trafficking [116, 117].

Chemokines are able of eliciting a variety of responses concerning leukocyte activation, degranulation and apoptosis, in addition same studies suggests that chemokines exert important actions on many cell types beyond the immune system, including endothelial cells (resulting in angiogenic, or angiostatic effects), smooth muscle cells, neurons and epithelial cells [118].

Chemokines can be shared in two groups: homeostatic chemokines (constitutively expressed in certain tissues and responsible of basal leukocyte trafficking), and inducible chemokines (upregulated by inflammatory stimuli, in the inflammatory reactions and inducing leukocyte recruitment) $[119,120]$.

The stimulus for the production of chemokines is a fundamental feature of the postinfarction inflammatory response [121-123].

Variuos experimental models of myocardial infarction showed a strong induction of several members of the chemokine family in the ischemic heart supporting their role in leukocyte recruitment, infarct angiogenesis and fibrous tissue deposition [124].

Monocyte chemoattractant protein (MCP)-1/CCL2 is expressed by mainly inflammatory cells and stromal cells, such as endothelial cells, mediates recruitment of mononuclear cells, modulates monocyte and lymphocyte phenotype and regulates fibrous tissue deposition and angiogenesis and its expression is upregulated after proinflammatory stimuli and tissue injury. MCP-1 can function as a traditional chemotactic cytokine and also regulates gene transcription, indeed MCP-1 is markedly induced in the infarcted myocardium and plays an important role in infarct healing and postinfarction remodeling [125]. In studies utilizing MCP-1 null mice was been demonstrated a decreasing macrophage recruitment in the infarcted heart, delayed phagocytosis of dead cardiomyocytes, diminished fibroblast infiltration and attenuated left ventricular remodeling [126]. During the inflammatory stage of infarct healing, MCP-1 mediates macrophage recruitment and timely clearance of dead cells from the infarct; however, prolonged induction of the chemokine in the infarcted heart may result in extension of granulation tissue formation and adverse remodeling of the ventricle [127]. The recently identified novel zinc-finger protein, called MCPIP (MCP-1-induced protein), promotes a series of signaling events that causes oxidative and endoplasmic reticulum (ER) stress, leading to autophagy that can result in cell death or differentiation, depending on the cellular context [128] (Fig. 2).

The mechanisms with MCP-1 causes migration of cells through binding to its receptor CCR2, present on the target cells, has been studied extensively [129]. Various studies demonstrated the role of MCP-1 in a variety of inflammatory diseases. The signal transduction events initiated by MCP-1 binding to CCR2 could result in induction of genes that could play a significant role in the development of inflammatory processes, but, the genes induced by MCP-1 and their potential role in inflammatory processes is not well understood $[130,131]$.

Experimental studies have identified a novel $\mathrm{CCCH}$ zinc finger protein, which was significantly induced by MCP-1 in human monocytes and thus designated as MCP-induced protein (MCPIP), as negative regulator of macrophage activation. 


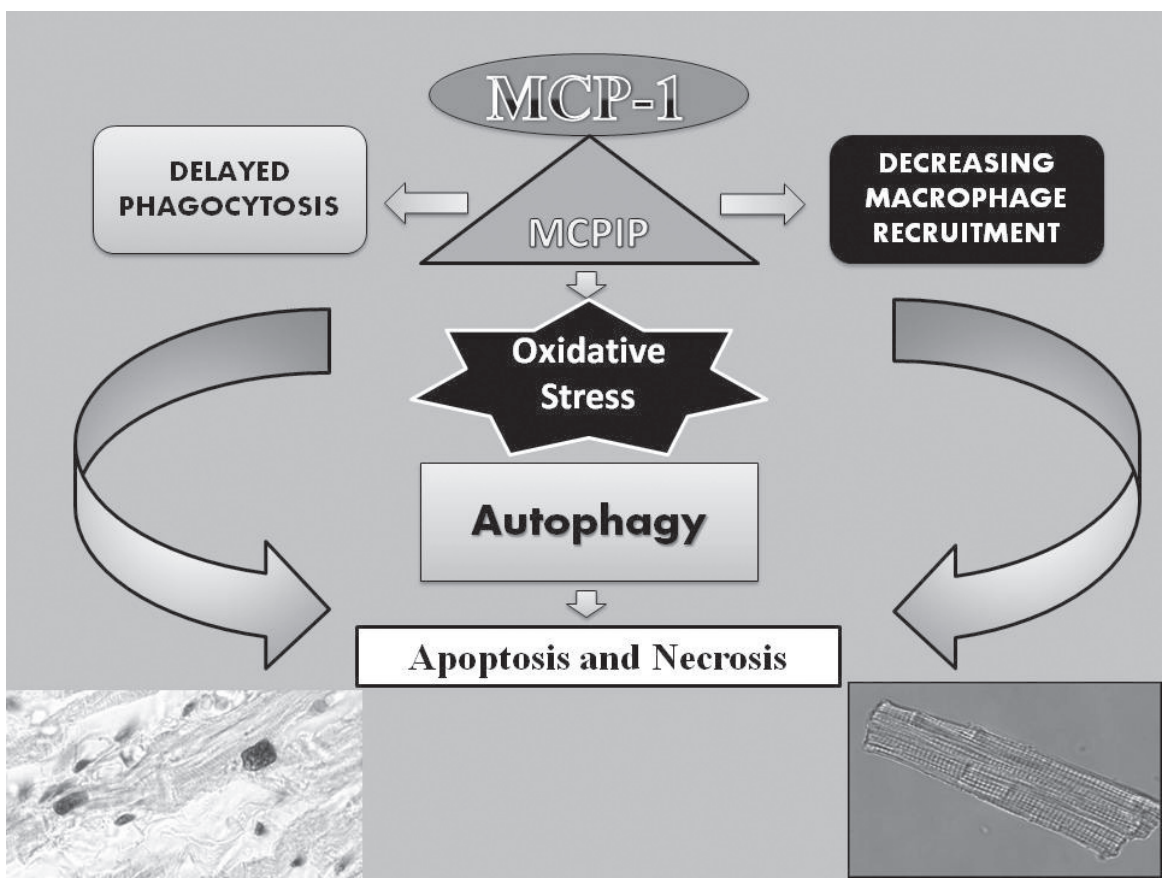

Fig. (2). Schematic representation of the MCP-1/MCPPIP-induced processes in myocardial infarcted.

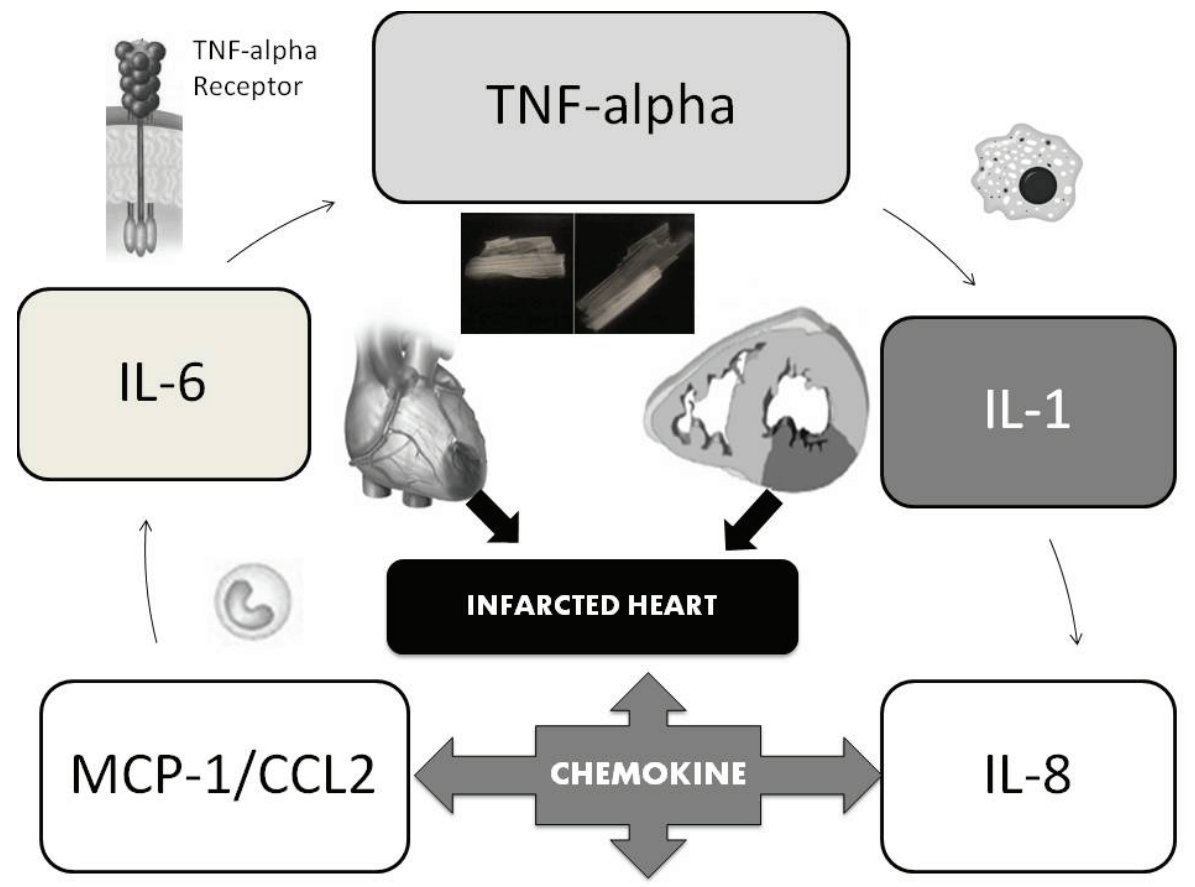

Fig. (3). Pro-inflammaroty cytokynes in the heart following acute ischemia.

The scientific evidence demonstrated that MCP-1 induction of a novel class of zinc-finger proteins in human peripheral blood monocytes is a consequence of the chain of events triggered by MCP-1 binding to CCR2 [131, 132]. The MCPIP turned out to be the first member of a novel family of $\mathrm{CCCH}$ zinc-finger proteins containing 4 members that we designate MCPIP 1, 2, 3, and 4, encoded by zc3h12a, zc3h12b, zc3h12c, and $\mathrm{z} 2 \mathrm{ch} 12 \mathrm{~d}$, respectively. 125 The best-studied member MCPIP1 is often simply called MCPIP. A genome-wide analysis of the $\mathrm{CCCH}$ zinc-finger gene family discovered 58 such genes in mice and 55 in humans. At least 7 of them were found to be expressed in macrophage-related organs such as thymus, spleen, lung, intestine, and adipose tissues [133]. MCPIP was found to be caplable to control inflammatory response by inhibition of nuclear factor- $\kappa \mathrm{B}$ activation through its deubiquitinase activity or by degradation of mRNA encoding a set of inflammatory cytokines through its RNase activity [128].

In the family of chemokine, IL-8/CXCL8 is the prototypic of $\mathrm{CXC}$ chemokine, and plays a critical role in regulation of neutrophil influx and activation with angiogenic properties [134-136]. 
In animal models (canine and rabbit) of experimental myocardial infarction the IL-8 upregulation has been explained [137, 138]. IL-8 induces the neutrophil respiratory burst and granule release, and enhances cellular adhesion, a $\beta 2$ integrin-dependent event. The activation of $\beta 2$-integrin induced by IL- 8 may be mediated through mitogen-activated protein kinase (MAPK) and protein kinase $\mathrm{C}$ (PKC) signaling. IL-8 may also have effects beyond its neutrophil chemotactic properties [139]. In a rabbit model study of myocardial ischemia-reperfusion injury the authors showed that IL-8 neutralization significantly reduces the degree of necrosis without affecting neutrophil infiltration [140] (Fig. 3).

\section{CONFLICT OF INTEREST}

The authors confirm that this article content has no conflict of interest.

\section{ACKNOWLEDGEMENTS}

Declared none.

\section{REFERENCES}

[1] Keeley EC, Boura JA, Grines CL. Primary angioplasty versus intravenous thrombolytic therapy for acute myocardial infarction: a quantitative review of 23 randomised trials. Lancet 2003; 361: 1320 .

[2] Penna C, Mancardi D, Raimondo S, Geuna S, Pagliaro P. The paradigm of postconditioning to protect the heart. J Cell Mol Med 2008; 12: 435-58

[3] Penna C, Mancardi D, Rastaldo R, Pagliaro P. Cardioprotection: a radical view Free radicals in pre and postconditioning. Biochim Biophys Acta 2009; 1787: 781-93.

[4] Pagliaro P, Moro F, Tullio F, Perrelli MG, Penna C. Cardioprotective pathways during reperfusion: focus on redox signaling and other modalities of cell signaling. Antioxid Redox Signal. 2011; 14: 833-50.

[5] Vinten-Johansen J, Granfeldt A, Mykytenko J, Undyala VV, Dong Y, Przyklenk K. The multidimensional physiological responses to postconditioning. Antioxid Redox Signal 2011; 14: 791-810.

[6] Golstein P, Kroemer G. Cell death by necrosis: towards a molecular definition. Trends Biochem Sci 2007; 32: 37-43.

[7] Zong WX, Thompson CB. Necrotic death as a cell fate. Genes Dev 2006; 20: 1-15.

[8] Takagi H, Matsui Y, Sadoshima J. The role of autophagy in mediating cell survival and death during ischemia and reperfusion in the heart. Antioxid Redox Signal 2007; 9: 1373-81.

[9] Perrelli MG, Pagliaro P, Penna C. Ischemia/reperfusion injury and cardioprotective mechanisms: role of mitochondria and reactive oxygen species. World J Cardiol 2011; 3(6): 186-200.

[10] Becker LB. New concepts in reactive oxygen species and cardiovascular reperfusion physiology. Cardiovasc Res 2004; 61(3): 46170 .

[11] Dhalla NS, Elmoselhi AB, Hata T, Makino N. Status of myocardial antioxidants in ischemia-reperfusion injury. Cardiovasc Res 2000; 47(3): 446-56

[12] Harling L, Rasoli S, Vecht JA, Ashrafian H, Kourliouros A, Athanasiou T. Do antioxidant vitamins have an anti-arrhythmic effect following cardiac surgery? A meta-analysis of randomised controlled trials. Heart 2011; 97(20): 1636-42.

[13] McColl AJ, Keeble T, Hadjinikolaou L, et al. Plasma antioxidants: evidence for a protective role against reactive oxygen species following cardiac surgery. Ann Clin Biochem 1998; 35: 616-23.

[14] Yusuf S, Dagenais G, Pogue J, Bosch J, Sleight P. Vitamin E supplementation and cardiovascular events in high-risk patients. The Heart Outcomes Prevention Evaluation Study Investigators. N Engl J Med 2000; 342(3): 154-60.
[15]

De Vecchi E, Pala MG, Di Credico G, et al. Relation between left ventricular function and oxidative stress in patients undergoing bypass surgery. Heart 1998; 79(3): 242-7.

[16] Hohensinner PJ, Niessner A, Huber K, Weyand CM, Wojta J. Inflammation and cardiac outcome. Curr Opin Infect Dis 2011; 24: 259-64.

[17] Linde A, Mosier D, Blecha F, Melgarejo T. Innate immunity and inflammation: new frontiers in comparative cardiovascular pathology. Cardiovasc Res 2007; 73: 26 -36

[18] Arslan F, de Kleijn DP, Pasterkamp G. Innate immune signaling in cardiac ischemia. Nat Rev Cardiol 2011; 8: 292-300.

[19] Herskowitz A, Choi S, Ansari AA,Wesselingh S. Cytokine mRNA expression in postischemic/reperfused myocardium. Am J Pathol 1995; 146: 419-28

[20] Nian M, Lee P, Khaper N, Liu P. Inflammatory cytokines and postmyocardial infarction remodeling. Circ Res 2004; 94: 1543-53.

[21] Frangogiannis NG, Youker KA, Rossen RD, et al. Cytokines and the microcirculation in ischemia and reperfusion. J Mol Cell Cardiol 1998; 30: 2567-76.

[22] Dewald O, Ren G, Duerr GD, et al. Of mice and dogs: speciesspecific differences in the inflammatory response following myocardial infarction. Am J Pathol 2004; 164: 665-77.

[23] Frangogiannis NG, Lindsey ML, Michael LH, et al. Resident cardiac mast cells degranulate and release preformed TNF-alpha, initiating the cytokine cascade in experimental canine myocardial ischemia/reperfusion. Circulation 1998; 98: 699-710.

[24] Kishimoto T, Akira S, Narazaki M, Taga T. Interleukin-6 family of cytokines and gp130. Blood 1995; 86: 1243-54.

[25] Frangogiannis NG. The immune system and cardiac repair. Pharmacological Research 2008; 58: 88-111.

[26] Kukreja RC, Emani VR, Hess ML. Activated oxygen species in heart failure. Heart Failure Rev 1999; 4: 121-32.

[27] Bolli R, Jeroudi MO, Patel BS, et al. Marked reduction of free radical generation and contractile dysfunction by antioxidant therapy begun at the time of reperfusion. Evidence that myocardial "stunning" is a manifestation of reperfusion injury. Circ Res 1989 , 65(3): 607-22

[28] Venardos KM, Perkins A, Headrick J, Kaye DM. Myocardial ischemia-reperfusion injury, antioxidant enzyme systems, and selenium: a review. Curr Med Chem 2007; 4(14): 1539-49.

[29] Cadet J, Douki T, Ravanat JL. Oxidatively generated damage to the guanine moiety of DNA: mechanistic aspects and formation in cells. Acc Chem Res 2008; 41: 1075-83.

[30] Teixeira MM, Cunha FQ, Noronha-Dutra A, Hothersall J. Production of singlet oxygen by eosinophils activated in vitro by $\mathrm{C} 5 \mathrm{a}$ and leukotriene B4. FEBS Lett 1999; 453: 265-8.

[31] Cilento G, Nascimento AL. Generation of electronically excited triplet species at the cellular level: a potential source of genotoxicity. Toxicol Lett 1993; 67: 17-28.

[32] Fukuto JM, Jackson MI, Kaludercic N, Paolocci N. Examining nitroxyl in biological systems. Methods Enzymol 2008; 440: 41131

[33] Donzelli S, Switzer CH, Thomas DD, et al. The activation of metabolites of nitric oxide synthase by metals is both redox and oxygen dependent: a new feature of nitrogen oxide signaling. Antioxid Redox Signal 2006; 8: 1363-71.

[34] Espey MG, Miranda KM, Thomas DD, et al. A chemical perspective on the interplay between NO, reactive oxygen species, and reactive nitrogen oxide species. Ann N Y Acad Sci 2002; 962: 195206.

[35] Grisham MB, Jourd'Heuil D, Wink DA. Nitric oxide. I. Physiological chemistry of nitric oxide and its metabolites: implications in inflammation. Am J Physiol Gastrointest Liver Physiol 1999; 276: G315-21.

[36] Hare JM, Stamler JS. NO/redox disequilibrium in the failing heart and cardiovascular system. J Clin Invest 2005; 115: 509-17.

[37] Mason RB, Pluta RM, Walbridge S, Wink DA, Oldfield EH, Boock RJ. Production of reactive oxygen species after reperfusion in vitro and in vivo: protective effect of nitric oxide. J Neurosurg 2000; 93: 99-107.

[38] Ridnour LA, Thomas DD, Mancardi D, et al. Antioxidant properties of nitric oxide in cellular physiological and pathophysiologica 
mechanisms. The implications of biological balance between NO and oxidative stress. Curr Med Chem - Anti-Inflamm AntiAllergy Agents 2004; 3: 181-8.

[39] Ridnour LA, Thomas DD, Mancardi D, et al. The chemistry of nitrosative stress induced by nitric oxide and reactive nitrogen oxide species. Putting perspective on stressful biological situations. Biol Chem 2004; 385: 1-10.

[40] Wink DA, Mitchell JB. Chemical biology of nitric oxide: insights into regulatory, cytotoxic, and cytoprotective mechanisms of nitric oxide. Free Radic Biol Med 1998; 25: 434-56.

[41] Hare JM. Nitroso-redox balance in the cardiovascular system. N Engl J Med 2004; 351: 2112-4.

[42] Wang P, Zweier JL. Measurement of nitric oxide and peroxynitrite generation in the postischemic heart. Evidence for peroxynitritemediated reperfusion injury. J Biol Chem 1996; 271(46): 29223-30.

[43] Habib F, Dutka D, Crossman D, Oakley CM, Cleland JG. Enhanced basal nitric oxide production in heart failure: another failed counter-regulatory vasodilator mechanism? Lancet 1994; 344(8919): 371-3.

[44] Levine B, Kalman J, Mayer L, Fillit HM, Packer M. Elevated circulating levels of tumor necrosis factor in severe chronic heart failure. N Engl J Med 1990; 323(4): 236-41.

[45] Roberts AB, Vodovotz Y, Roche NS, Sporn MB, Nathan CF. Role of nitric oxide in antagonistic effects of transforming growth factor-beta and interleukin-1 beta on the beating rate of cultured cardiac myocytes. Mol Endocrinol 1992; 6(11): 1921-30.

[46] Hudson KF. A phenomenon of paradox: myocardial reperfusion injury. Heart Lung 1994; 23(5): 384-93.

[47] Kadkhodaee M, Endre ZH, Towner RA, Cross M. Hydroxyl radical generation following ischaemia-reperfusion in cell-free perfused rat kidney. Biochim Biophys Acta 1995; 1243(2): 169-74.

[48] Hearse DJ. Stunning: a radical re-view. Cardiovasc Drugs Ther 1991; 5(5): 853-76.

[49] Ferrari R, Ceconi C, Curello S, Alfieri O, Visioli O. Myocardial damage during ischaemia and reperfusion. Eur Heart J 1993; 14 Suppl G: 25-30.

[50] Grace PA. Ischaemia-reperfusion injury. Br J Surg 1994; 81(5): 637-47.

[51] Berry CE, Hare JM. Xanthine oxidoreductase and cardiovascular disease: molecular mechanisms and pathophysiological implications. J Physiol 2004; 555: 589-606

[52] Di Lisa F, Canton M, Menabò R, Kaludercic N, Bernardi P. Mitochondria and cardioprotection. Heart Fail. Rev 2007; 12: 249-60.

[53] Weiss JN, Korge P, Honda HM, Ping P. Role of the mitochondrial permeability transition in myocardial disease. Circ Res 2003; 93(4): 292-301.

[54] Singal PK, Beamish RE, Dhalla NS. Potential oxidative pathways of catecholamines in the formation of lipid peroxides and genesis of heart disease. Adv Exp Med Biol 1983; 161: 391-401.

[55] Fineschi V, Baroldi G, Centini F, et al. Markers of cardiac oxidative stress and altered morphology after intraperitoneal cocaine injection in a rat model. Int J Legal Med 2001; 114(6): 323-30.

[56] Cerretani D, Fineschi V, Bello S, Riezzo I, Turillazzi E, Neri M. Role of Oxidative Stress in Cocaine-induced Cardiotoxicity and Cocaine-related Death. Curr Med Chem 2012; 19: 5619-23

[57] Cerretani D, Riezzo I, Fiaschi AI, et al. Cardiac oxidative stress determination and myocardial morphology after a single ecstasy (MDMA) administration in a rat model. Int J Legal Med 2008; 122(6): 461-9

[58] Neri M, Cerretani D, Fiaschi AI, et al. Correlation between cardiac oxidative stress and myocardial pathology due to acute and chronic norepinephrine administration in rats. J Cell Mol Med 2007; 11(1): 156-70.

[59] Dhalla NS, Adameova A, Kaur M. Role of catecholamine oxidation in sudden cardiac death. Fundam Clin Pharmacol 2010; 24: 539-46.

[60] Adameova A, Abdellatif Y, Dhalla N.S. Role of the excessive amounts of circulating catecholamines and glucocorticoids in stress-induced heart disease. Can J Physiol Pharmacol 2009; 87: 493-514.

[61] Dhalla NS, Temsah RM, Netticadan T, et al. Calcium overload in ischemia/reperfusion injury. In: Sperelakis N, Kurachi Y, Terzic A,
Cohen M. Heart physiology and pathophysiology, 4th edn, Academic Press, San Diego, 2001; pp. 949-65.

[62] Ferrari R, Ferrari F, Benigno M, Pepi P, Visioli O. Hibernating myocardium: its pathophysiology and clinical role. Mol Cell Biochem 1998; 186(1-2): 195-9.

[63] Piper HM, García-Dorado D, Ovize M. A fresh look at reperfusion injury. Cardiovasc Res 1998; 38(2): 291-300.

[64] Duncker DJ, Schulz R, Ferrari R, et al. "Myocardial stunning" remaining questions. Cardiovasc Res 1998; 38(3): 549-58.

[65] Kloner RA, Przyklenk K, Whittaker P. Deleterious effects of oxygen radicals in ischemia/reperfusion. Resolved and unresolved issues. Circulation 1989; 80(5): 1115-27.

[66] Molavi B, Mehta JL. Oxidative stress in cardiovascular disease: molecular basis of its deleterious effects, its detection, and therapeutic considerations. Curr Opin Cardiol 2004; 19(5): 488-93.

[67] Kaneko M, Singal PK, Dhalla NS. Alterations in heart sarcolemmal $\mathrm{Ca} 2(+)$-ATPase and $\mathrm{Ca} 2(+)$-binding activities due to oxygen free radicals. Basic Res Cardiol 1990; 85: 45-54.

[68] Perez NG, Gao WD, Marban E. Novel myofilament Ca2+sensitizing property of xanthine oxidase inhibitors. Circ Res 1998; 83: 423-30.

[69] Valko M, Leibfritz D, Moncol J, Cronin MT, Mazur M, Telser J. Free radicals and antioxidants in normal physiological functions and human disease. Int J Biochem Cell Biol 2007; 39(1): 44-84

[70] Masella R, Di Benedetto R, Varì R, Filesi C, Giovannini C. Novel mechanisms of natural antioxidant compounds in biological systems: involvement of glutathione and glutathione-related enzymes. J Nutr Biochem 2005; 16(10): 577-86.

[71] Pastore A, Federici G, Bertini E, Piemonte F. Analysis of glutathione: implication in redox and detoxification. Clin Chim Acta 2003; 333(1): 19-39.

[72] Akila BD, Vishwanath P, D'souza V. Oxidative injury and antioxidants in coronary artery bypass graft surgery: Off-pump CABG significantly reduces oxidative stress. Clin Chim Acta 2007; 375: 147-52.

[73] Weinbrenner T, Cladellas M, Covas MI, et al. High oxidative stress in patients with stable coronary heart disease. Atherosclerosis 2003; 168: 99-106.

[74] Kesavulu MM, Rao BK, Giri R, Vijaya J, Subramanyam G, Apparao C. Lipid peroxidation and antioxidant enzyme status in Type 2 diabetics with coronary heart disease. Diabetes Res Clin Pract 2001; 53: 33-9.

[75] Bagatini MD, Martins CC, Battisti V, et al. Oxidative stress versus antioxidant defenses in patients with acute myocardial infarction. Heart Vessels 2011; 26(1): 55-63.

[76] Senthil S, Veerappan RM, Ramakrishna RM, Pugalendi KV. Oxidative stress and antioxidants in patients with cardiogenic shock complicating acute myocardial infarction. Clin Chim Acta 2004; 348: 131-7.

[77] Pandey NR, Kaur G, Chandra M, Sanwal GG, Misra MK. Enzymatic oxidant and antioxidants of human blood platelets in unstable angina and myocardial infarction. Int J Cardiol 2000; 76: 33-8.

[78] Zhou X, Zhai X, Ashraf M. Direct evidence that initial oxidative stress triggered by preconditioning contributes to second window of protection by endogenous antioxidant enzyme in myocytes. Circulation 1996; 93: 1177-84.

[79] Nikolic-Heitzler V, Rabuzin F, Tatzber F, et al. Persistent oxidative stress after myocardial infarction treated by percutaneous coronary intervention. J Exp Med 2006; 210: 247-55.

[80] Bodmer JL, Schneider P, Tschopp J. The molecular architecture of the TNF superfamily. Trends Biochem Sci 2002; 27: 19-26

[81] Locksley RM, Killeen N, Lenardo MJ. The TNF and TNF receptor superfamilies: integrating mammalian biology. Cell 2001; 104 487-501.

[82] Engel D, Peshock R, Armstong RC, Sivasubramanian N, Mann DL. Cardiac myocyte apoptosis provokes adverse cardiac remodeling in transgenic mice with targeted TNF overexpression. Am J Physiol Heart Circ Physiol 2004; 287: H1303-11.

[83] Finkel MS, Oddis CV, Jacob TD, Watkins SC, Hattler BG, Simmons RL. Negative inotropic effects of cytokines on the heart mediated by nitric oxide. Science 1992; 257: 387-9. 
[84] Yokoyama T, Vaca L, Rossen RD, Durante W, Hazarika P, Mann DL. Cellular basis for the negative inotropic effects of tumor necrosis factor-alpha in the adult mammalian heart. J Clin Invest 1993; 92: 2303-12.

[85] Siwik DA, Chang DL, Colucci WS. Interleukin-1beta and tumor necrosis factor alpha decrease collagen synthesis and increase matrix metalloproteinase activity in cardiac fibroblasts in vitro. Circ Res 2000; 86: 1259-65.

[86] Sun M, Dawood F, Wen WH, et al. Excessive tumor necrosis factor activation after infarction contributes to susceptibility of myocardial rupture and left ventricular dysfunction. Circulation 2004; 110: 3221-8.

[87] Maekawa N, Wada H, Kanda T, et al. Improved myocardial ischemia/reperfusion injury in mice lacking tumor necrosis factor alpha. J Am Coll Cardiol 2002; 39: 1229-35.

[88] Berthonneche C, Sulpice T, Boucher F, et al. New insights into the pathological role of TNF-alpha in early cardiac dysfunction and subsequent heart failure after infarction in rats. Am J Physiol Heart Circ Physiol 2004; 287: H340-50.

[89] Sugano M, Tsuchida K, Hata T, Makino N. In vivo transfer of soluble TNF alpha receptor 1 gene improves cardiac function and reduces infarct size after myocardial infarction in rats. FASEB $\mathrm{J}$ 2004; 18: 911-3.

[90] Monden Y, Kubota T, Tsutsumi T, et al. Soluble TNF receptors prevent apoptosis in infiltrating cells and promote ventricular rupture and remodeling after myocardial infarction. Cardiovasc Res 2007; 73: 794-805.

[91] Kurrelmeyer KM, Michael LH, Baumgarten G, et al. Endogenous tumor necrosis factor protects the adult cardiac myocyte against ischemic-induced apoptosis in a murine model of acute myocardial infarction. Proc Natl Acad Sci USA 2000; 97: 5456-61.

[92] Monden Y, Kubota T, Inoue T, et al. Tumor necrosis factor-alpha is toxic via receptor 1 and protective via receptor 2 in a murine model of myocardial infarction. Am J Physiol Heart Circ Physiol 2007; 293: H743-53.

[93] Yu X, Deng L, Wang D, et al. Mechanism of TNF- $\alpha$ autocrine effects in hypoxic cardiomyocytes: Initiated by hypoxia inducible factor $1 \alpha$, presented by exosomes. J Mol Cell Cardiol. 2012; 53(6): 848-57.

[94] Kehmeier ES, Lepper W, Kropp M, et al. TNF- $\alpha$, myocardial perfusion and function in patients with ST-segment elevation myocardial infarction and primary percutaneous coronary intervention. Clin Res Cardiol 2012; 101(10): 815-27.

[95] Dinarello CA. Biologic basis for interleukin-1 in disease. Blood 1996; 87: 2095-147.

[96] Dobaczewski M, Bujak M, Zymek P, Ren G, Entman ML, Frangogiannis NG. Extracellular matrix remodeling in canine and mouse myocardial infarcts. Cell Tissue Res 2006; 324: 475-88.

[97] Guillen I, Blanes M, Gomez-Lechon MJ, Castell JV. Cytokine signaling during myocardial infarction: sequential appearance of IL-1 beta and IL-6. Am J Physiol 1995; 269: R229-35.

[98] Suzuki K, Murtuza B, Smolenski RT, et al. Overexpression of interleukin-1 receptor antagonist provides cardioprotection against ischemia-reperfusion injury associated with reduction in apoptosis. Circulation 2001; 104: I303-8.

[99] Hwang MW, Matsumori A, Furukawa Y, et al. Neutralization of interleukin-1beta in the acute phase of myocardial infarction promotes the progression of left ventricular remodeling. J Am Coll Cardiol 2001; 38: 1546-53.

[100] Bujak M, Dobaczewski M, Chatila K, et al. Interleukin-1 receptor type I signaling critically regulates infarct healing and cardiac remodeling. Am J Pathol 2008; 173: 57-67.

[101] Bujak M, Frangogiannis NG. The role of IL-1 in the pathogenesis of heart disease. Arch Immunol Ther Exp 2009; 57: 165-176.

[102] Toldo S, Schatz AM, Mezzaroma E, et al. Recombinant human interleukin-1 receptor antagonist provides cardioprotection during myocardial ischemia reperfusion in the mouse. Cardiovasc Drugs Ther 2012; 26(3): 273-6.

[103] Aoyama T, Takimoto Y, Pennica D, et al. Augmented expression of cardiotrophin-1 and its receptor component, gp130, in both left and right ventricles after myocardial infarction in the rat. $\mathrm{J}$ Mol Cell Cardiol 2000; 32: 1821-30.
[104] Gwechenberger M, Mendoza LH, Youker KA, et al. Cardiac myocytes produce interleukin- 6 in culture and in viable border zone of reperfused infarctions. Circulation 1999; 99: 546-51.

[105] Kukielka GL, Smith CW, Manning AM, Youker KA, Michael LH, Entman ML. Induction of interleukin-6 synthesis in the myocardium. Potential role in postreperfusion inflammatory injury. Circulation 1995; 92: 1866-75.

[106] Freed DH, Moon MC, Borowiec AM, Jones SC, Zahradka P, Dixon IM. Cardiotrophin-1: expression in experimental myocardial infarction and potential role in post-MI wound healing. Mol Cell Biochem 2003; 254: 247-56

[107] Gwechenberger M, Moertl D, Pacher R, Huelsmann M. Oncostatin$\mathrm{M}$ in myocardial ischemia/reperfusion injurymay regulate tissue repair. Croat Med J 2004; 45: 149-57.

[108] Wollert KC, Drexler H. The role of interleukin-6 in the failing heart. Heart Fail Rev 2001; 6: 95-103.

[109] Liao Z, Brar BK, Cai Q, et al. Cardiotrophin-1 (CT-1) can protect the adult heart from injury when added both prior to ischaemia and at reperfusion. Cardiovasc Res 2002; 53: 902-10.

[110] Gritman K, Van Winkle DM, Lorentz CU, Pennica D, Habecker BA. The lack of cardiotrophin-1 alters expression of interleukin- 6 and leukemia inhibitory factor mRNA but does not impair cardiac injury response. Cytokine 2006; 36: 9-16.

[111] Freed DH, Cunnington RH, Dangerfield AL, Sutton JS, Dixon IM. Emerging evidence for the role of cardiotrophin-1 in cardiac repair in the infarcted heart. Cardiovasc Res 2005; 65: 782-92.

[112] Zou Y, Takano H, Mizukami M, et al. Leukemia inhibitory factor enhances survival of cardiomyocytes and induces regeneration of myocardium after myocardial infarction. Circulation 2003; 108: 748-53.

[113] Gallucci RM, Simeonova PP, Matheson JM, et al. Impaired cutaneous wound healing in interleukin-6-deficient and immunosuppressed mice. FASEB J 2000; 14: 2525-31.

[114] Fuchs M, HilfikerA, Kaminski K, et al. Role of interleukin-6 for LV remodeling and survival after experimental myocardial infarction. FASEB J 2003; 17: 2118-20.

[115] Clark-Lewis I, Kim KS, et al. Structure-activity relationships of chemokines. J Leukoc Biol 1995; 57: 703-11.

[116] Gerard C, Rollins BJ. Chemokines and disease. Nat Immunol 2001; 2: $108-15$.

[117] Moser B, Loetscher P. Lymphocyte traffic control by chemokines.Nat Immunol 2001; 2: 123-8.

[118] Strieter RM, Polverini PJ, Arenberg DA, et al. Role of C-X-C chemokines as regulators of angiogenesis in lung cancer. J Leukoc Biol 1995; 57: 752-62.

[119] Zlotnik A, Morales J, Hedrick JA. Recent advances in chemokines and chemokine receptors. Crit Rev Immunol 1999; 19: 1-47.

[120] Zlotnik A, Yoshie O. Chemokines: a new classification system and their role in immunity. Immunity 2000; 12: 121-7.

[121] Frangogiannis NG. Chemokines in ischemia and reperfusion. Thromb Haemost 2007; 97: 738-47.

[122] Frangogiannis NG. Chemokines in the ischemic myocardium: from inflammation to fibrosis. Inflamm Res 2004; 53: 585-95.

[123] Frangogiannis NG. The role of the chemokines in myocardial ischemia and reperfusion. Curr Vasc Pharmacol 2004; 2: 163-74.

[124] Frangogiannis NG, Mendoza LH, Lewallen M, Michael LH, Smith $\mathrm{CW}$, Entman ML. Induction and suppression of interferoninducible protein 10 in reperfused myocardial infarcts may regulate angiogenesis. FASEB J 2001; 15: 1428-30.

[125] Xia Y, Frangogiannis NG. MCP-1/CCL2 as a therapeutic target in myocardial infarction and ischemic cardiomyopathy. Inflamm Allergy Drug Targets 2007; 6(2): 101-7.

[126] Dewald O, Zymek P, Winkelmann K, et al. CCL2/monocyte chemoattractant protein-1 regulates inflammatory responses critical to healing myocardial infarcts. Circ Res 2005; 96: 881-9.

[127] Frangogiannis NG, Ren G, Dewald O, et al. The critical role of endogenous thrombospondin (TSP)-1 in preventing expansion of healing myocardial infarcts. Circulation 2005; 111: 2935- 42.

[128] Kolattukudy PE, Niu J. Inflammation, Endoplasmic Reticulum Stress, Autophagy, and the Monocyte Chemoattractant Protein1/CCR2 Pathway. Circ Res. 2012; 110(1): 174-89. 
[129] Niu J, Kolattukudy PE. Role of MCP-1 in cardiovascular disease: molecular mechanisms and clinical implications. Clin Sci (Lond). 2009; 117: 95-109.

[130] Deshmane SL, Kremlev S, Amini S, Sawaya BE. Monocyte chemoattractant protein-1 (MCP-1): an overview. J Interferon Cytokine Res 2009; 29: 313-26.

[131] Liang J, Song W, Tromp G, Kolattukudy PE, Fu M. Genome-wide survey and expression profiling of $\mathrm{CCCH}$-zinc finger family reveals a functional module in macrophage activation. PLoS One 2008; 3: e2880.

[132] Zhou L, Azfer A, Niu J, et al. Monocyte chemoattractant protein-1 induces a novel transcription factor that causes cardiac myocyte apoptosis and ventricular dysfunction. Circ Res 2006; 98: 1-10.

[133] Liang J, Wang J, Azfer A, et al. A novel CCCH-zinc finger protein family regulates proinflammatory activation of macrophages. J Biol Chem 2008; 283: 6337-46.

[134] Mukaida N. Interleukin-8: an expanding universe beyond neutrophil chemotaxis and activation. Int J Hematol 2000; 72: 391-8.
[135] Zeilhofer HU, Schorr W. Role of interleukin-8 in neutrophil signaling. Curr Opin Hematol 2000; 7: 178-82.

[136] Koch AE, Polverini PJ, Kunkel SL, et al. Interleukin-8 as a macrophage-derived mediator of angiogenesis. Science 1992; 258: 1798801.

[137] Kukielka GL, Smith CW, La Rosa GJ, et al. Interleukin-8 gene induction in the myocardium after ischemia and reperfusion in vivo. J Clin Invest 1995; 95: 89-103.

[138] Ivey CL, Williams FM, Collins PD, Jose PJ, Williams TJ. Neutrophil chemoattractants generated in two phases during reperfusion of ischemic myocardium in the rabbit. Evidence for a role for C5a and interleukin-8. J Clin Invest 1995; 95: 2720-8.

[139] Takami M, Terry V, Petruzzelli L. Signaling pathways involved in IL-8- dependent activation of adhesion through Mac-1. J Immunol 2002; 168: 4559-66.

[140] Boyle Jr EM, Kovacich JC, Hebert CA, et al. Inhibition of interleukin-8 blocks myocardial ischemia-reperfusion injury. J Thorac Cardiovasc Surg 1998; 116: 114-21.

Received: September 21, 2012 Revised: November 2, 2012 Accepted: November 2, 2012 